UDK 528.14

\title{
GEODEZINIO VERTIKALIOJO TINKLO IŠLYGINIMO MODELIS ELIMINUOJANT SISTEMINGĄSIAS KLAIDAS
}

\author{
Jonas Skeivalas \\ Geodezijos ir kadastro katedra, Vilniaus Gedimino technikos universitetas, \\ Saulètekio al. 11, LT-10223 Vilnius, Lietuva, \\ el.paštas Jonas.Skeivalas@ap.vgtu.lt
}

lteikta 200701 22, priimta 20070330

\begin{abstract}
Santrauka. Normalinių aukščiu tikslumo nustatymas geodezinėje praktikoje yra pakankamai aktuali ir sudètinga problema, susijusi su taikomais aukščių nustatymo metodais bei geofizinemis konstantomis. Šiame straipsnyje analizuojamas papildomų parametrų ir sąlyginių lygčių taikymas vertikaliojo tinklo išlyginimo procedūrose, siekiant eliminuoti niveliavimo matavimų sistemingassias klaidas. Tinklo išlyginimas atliekamas mažiausiuju kvadratų metodu. Išlygintųjų dydžių ir parametrų tikslumas ịvertinamas kovariacijų matricų pavidalu.
\end{abstract}

Reikšminiai žodžiai: vertikalusis tinklas, atsitiktinès ir sistemingosios klaidos, mažiausiųjų kvadratų metodas, kovariacijų matrica.

\section{Ivadas}

Vertikalieji tinklai sudaromi pagal aukščiu matavimų duomenis, siekiant detaliai nustatyti Žemės paviršiaus formą. Tai būtina atliekant geoido nustatymo, geofizinius, geodinaminius tyrimus, kartografavimo darbus, jūros lygio matavimus bei kitiems poreikiams. Atliekant geodezinius matavimus taikoma tokia aukščiu sistema, kurioje bet kurio taško aukštis, nustatytas niveliuojant, nepriklauso nuo niveliavimo kelio. Tokią nuostatą atitinka normalinių ir ortometrinių aukščiu sistemos. Ortometriniams aukščiams skaičiuoti būtina žinoti Žemès plutos sandarą ir vidutinę realiojo sunkio $g$ nustatomame taške reikšmę $g_{m}$ linijos atkarpoje tarp geoido ir Žemès paviršiaus taško. Praktikoje tai igyvendinti neįmanoma. Todèl sudarant valstybines aukščiu sistemas taikoma normalinių aukščių sistema. Ši sistema pagrịsta rusų mokslininko M. S. Molodenskio sukurta teorija, pagal kurią normaliniams aukščiams skaičiuoti taikoma normalinio sunkio $\gamma$ aukštyje $\bar{H}=1 / 2 H_{A}$ virš elipsoido reikšmé $\bar{\gamma}$. Normaliniam sunkiui $\gamma$ reikiamu tikslumu nustatyti taikomi atitinkami metodai. Taigi normalinis aukštis nustatomas kaip normalès i elipsoidą atkarpa, atideta tarp kvazigeoido ir Žemès paviršiaus taško. Tokiu būdu Žemès paviršiaus taško aukštis $H_{A}$ šioje sistemoje nustatomas vienareikšmiškai.

Normalinių aukščių tikslumas geodezinejje praktikoje yra pakankamai aktuali ir sudètinga problema, susijusi ir su taikomais aukščiu nustatymo metodais, ir su geofizinėmis konstantomis. Šie matavimai atliekami remiantis IGSN 71 sunkio sistema [1, 5]. Taikoma LKS 94 koordinačiu sistema bei GRS 80 normalusis sunkio laukas.
Aukščiu matavimų rezultatuose visada esti klaidų ir atsitiktiniu, ir sistemingujų [1-6]. Todèl būtini atitinkami matavimo rezultatų apdorojimo metodai, kuriuos taikant galima būtų efektyviau eliminuoti įvairias matavimų klaidas. Vienas iš metodų matavimų sistemingosioms klaidoms eliminuoti yra papildomu parametrų taikymas išlyginimo procedūrose [2, 6].

Šiame straipsnyje analizuojama papildomu parametrų taikymas siekiant eliminuoti sistemingąsias niveliavimo matavimų klaidas.

\section{Išlyginimo teorinis modelis}

Vertikaliuosiuose tinkluose matavimo rezultatams apdoroti racionaliausia taikyti mažiausiujuc kvadratu metodą ir papildomus parametrus. Šiuo metodu galima, naudojant atitinkamą programinę ịrangą, automatiškai sudaryti kompiuterinę parametrinių lygčių sistemą. Aukščiu tinklo eigu matavimo rezultatų kokybe kontroliuojama pagal aukščiu dvigubujų matavimų duomenu skirtumus bei pagal tų pačių aukščiu nesutapimus poligonuose. Taikant papildomus parametrus aukščių tinklų apdorojimo procedūrose galima pasirinktinai kontroliuoti ir, remiantis nusistatytaja tikimybe, eliminuoti pavienių aukščių tinklo eigu sistemingąsias klaidas. Visų eigu to padaryti neịmanoma, nes turi būti paisoma nelygybès salygos, kad išmatuotų dydžių skaičius $n$ būtų didesnis už bendraji parametrų skaičių $k+s$, t. y. $n>k+s$, čia $k, s-$ atitinkamai pagrindinių ir papildomų parametrų skaičius.

Taikydami papildomus parametrus $\delta$ kaip aukščiu eigu sistemingąsias klaidas ir sąlygines pataisų lygtis, galime sudaryti šią pataisų ir sąlyginių lygčių sistemą: 


$$
\left.\begin{array}{l}
\boldsymbol{V}=\boldsymbol{A} \tau+\boldsymbol{C} \boldsymbol{\delta}+\boldsymbol{L} \\
\boldsymbol{A}_{\boldsymbol{r}} \boldsymbol{\delta}+\boldsymbol{\omega}^{\prime \prime}=0
\end{array}\right\}
$$

čia $\boldsymbol{V}$ - pataisų vektorius $(n \times 1), \tau-$ aukščių, kaip pagrindinių parametru, pataisų vektorius $(k \times 1), \delta-$ aukščiu skirtumu pataisų vektorius $(n \times 1), \boldsymbol{A}$ - pataisu lygčių koeficientų matrica $(n \times k), C$ - papildomų parametrų pataisų lygtyse koeficientų matrica $(n \times n)$, $\boldsymbol{A}_{\boldsymbol{r}}$ - sąlyginių pataisų lygčių koeficientų matrica $(r \times n)$; $\boldsymbol{L}, \boldsymbol{\omega}^{\prime \prime}$ - laisvuju narių vektoriai, $\boldsymbol{L}=\boldsymbol{A} \boldsymbol{H}-\boldsymbol{h}, \boldsymbol{H}-$ tašku aukščiu apytikrių reikšmių vektorius, $\boldsymbol{h}$ - išmatuotų aukščiu skirtumu vektorius. Vektoriuje $\delta$ nulinių elementų skaičius yra lygus $n-s$. Sąlyginių lygčių laisvujų narių vektorius $\omega^{\prime \prime}$ apskaičiuojamas pagal formulę

$$
\omega^{\prime \prime}=A_{r} B+A_{u} H_{u},
$$

čia $\boldsymbol{A}_{\boldsymbol{u}}$ - pradinių duomenų koeficientų matrica $(r \times u)$, $\boldsymbol{H}_{\boldsymbol{u}}$ - pradinių duomenų vektorius, $r$ - sąlyginių lygčių skaičius, $u$ - pradinių duomenų skaičius.

Sąlyginiu lygčiu formavimo procedūros gali būti įvairios priklausomai nuo aukščiu tinklo sudètingumo, aukščiu skirtumų matavimų tikslumo ir kt.

Matavimų rezultatams apdoroti taikome mažiausiujuc kvadratų metodo sąlyga

$$
\Phi=V^{T} P V+2 k^{T}\left(A_{r}+\omega^{\prime \prime}\right)=\min
$$

Pagal (3) sąlygą gauname:

$$
\begin{aligned}
& \frac{\partial \Phi}{\partial \tau}=2 \boldsymbol{A}^{\boldsymbol{T}} \boldsymbol{P} \boldsymbol{V}=0, \\
& \frac{\partial \Phi}{\partial \boldsymbol{\delta}}=2 \boldsymbol{C}^{\boldsymbol{T}} \boldsymbol{P} \boldsymbol{V}+2 \boldsymbol{A}_{\boldsymbol{r}}^{\boldsymbol{T}} \boldsymbol{k}=0,
\end{aligned}
$$

čia $\boldsymbol{P}$ - svorių matrica $(n \times n), \boldsymbol{k}$ - koreliatų vektorius $(r \times 1)$.

Normalinių lygčių sistemos igyja išraišką

$$
\left.\begin{array}{l}
A^{T} P A \tau+A^{T} P C \delta+A^{T} P L=0 \\
C^{T} P A \tau+C^{T} P C \delta+A_{r}^{T} k+C^{T} P L=0
\end{array}\right\}
$$

Prie šios sistemos prijungiame sąlyginių pataisų lygčiu sistemą iš bendrosios sistemos (1). Bendroji normalinių lygčių sistema išreikšta blokinėmis matricomis:

$$
\left(\begin{array}{ll|l}
\boldsymbol{N}_{11} & \boldsymbol{N}_{12} & 0 \\
\boldsymbol{N}_{21} & \boldsymbol{N}_{22} & A_{r}^{T} \\
\hline 0 & \boldsymbol{A}_{r} & 0
\end{array}\right)\left(\begin{array}{c}
\boldsymbol{\tau} \\
\boldsymbol{\delta} \\
\boldsymbol{k}
\end{array}\right)+\left(\begin{array}{c}
\boldsymbol{\omega} \\
\boldsymbol{\omega}^{\prime} \\
\boldsymbol{\omega}^{\prime \prime}
\end{array}\right)=0
$$

čia $\omega=A^{T} P L, \omega^{\prime}=C^{T} P L$.
Pastaroji normalinių lygčių sistema kitokiu blokiniu pavidalu užrašoma:

$$
\left(\begin{array}{cc}
N_{11}^{\prime} & N_{12}^{\prime} \\
N_{21}^{\prime} & 0
\end{array}\right)\left(\begin{array}{l}
\tau \\
\delta \\
k
\end{array}\right)+\left(\begin{array}{c}
\omega \\
\omega^{\prime} \\
\omega^{\prime \prime}
\end{array}\right)=0
$$

čia $N_{11}^{\prime}=\left(\begin{array}{ll}N_{11} & N_{12} \\ N_{21} & N_{22}\end{array}\right), \quad N_{12}^{\prime}=\left(\begin{array}{c}0 \\ A_{r}^{T}\end{array}\right), \quad N_{21}^{\prime}=\left(0 \mid A_{r}\right)$.

Lygčių sistemos (6) sprendinys

$$
\tau_{0}=\left(\begin{array}{l}
\tau \\
\delta \\
k
\end{array}\right)=-\left(\begin{array}{cc}
N_{11}^{\prime} & N_{12}^{\prime} \\
N_{21}^{\prime} & 0
\end{array}\right)^{-1}\left(\begin{array}{c}
\omega \\
\omega^{\prime} \\
\omega^{\prime \prime}
\end{array}\right)=-Q \omega_{0},
$$

čia $\omega_{0}=\left(\begin{array}{lll}\omega^{T} & \omega^{\prime T} & \omega^{\prime \prime T}\end{array}\right)^{T}, \quad \tau_{0}=\left(\begin{array}{l}\tau^{T} \delta^{T} k^{T}\end{array}\right)^{T}$.

Atvirkštinę blokinę matrica, taikydami K. R. Koch formulę, galime užrašyti šiuo pavidalu [2]:

$$
\begin{gathered}
\boldsymbol{Q}=\left(\begin{array}{cc}
\boldsymbol{N}_{11}^{\prime} & \boldsymbol{N}_{12}^{\prime} \\
\boldsymbol{N}_{21}^{\prime} & 0
\end{array}\right)^{-1}=\left(\begin{array}{ll}
\boldsymbol{Q}_{11} & \boldsymbol{Q}_{12} \\
\boldsymbol{Q}_{21} & \boldsymbol{Q}_{22}
\end{array}\right)= \\
\left.\frac{\boldsymbol{N}_{11}^{\prime-1}+\boldsymbol{F}^{\prime} \boldsymbol{H}^{\prime-1} \boldsymbol{F}^{\prime \boldsymbol{T}} \mid-\boldsymbol{F}^{\prime} \boldsymbol{H}^{\prime-1}}{-\boldsymbol{H}^{\prime-1} \boldsymbol{F}^{\prime \boldsymbol{T}} \mid \boldsymbol{H}^{\prime-1}}\right)
\end{gathered}
$$

čia $F^{\prime}=N_{11}^{\prime-1} N_{12}^{\prime}, \quad H^{\prime}=N_{22}^{\prime}-N_{21}^{\prime} N_{11}^{\prime-1} N_{12}^{\prime}=N_{22.1}^{\prime}=$ $-N_{21}^{\prime} N_{11}^{\prime-1} N_{12}^{\prime}$.

Vektoriu $\tau, \delta$ ir $\boldsymbol{k}$ tikslumas ivertinamas kovariacijų matrica $\boldsymbol{K}_{\tau_{0}}$ :

$$
K_{\tau_{0}}=Q K_{\omega_{0}} Q
$$

Laisvujų narių vektoriaus $\boldsymbol{\omega}_{0}$ kovariacijų matrica $\boldsymbol{K}_{\boldsymbol{\omega}_{0}}$ yra lygi

$$
\begin{aligned}
& K_{\omega_{0}}=K\left\{\left(\begin{array}{c}
A^{T} P L \\
C^{T} P L \\
A_{r} B+A_{u} H_{u}
\end{array}\right)\right\}=K\left\{\left(\begin{array}{l}
A^{T} P(A T-B) \\
C^{T} P(A T-B) \\
A_{r} B+A_{u} H_{u}
\end{array}\right)\right\}= \\
& K\left\{\left(\begin{array}{c}
A^{T} P A T \\
C^{T} P A T \\
A_{u} H_{u}
\end{array}\right)\right\}+K\left\{\left(\begin{array}{c}
-A^{T} P B \\
-C^{T} P B \\
A_{r} B
\end{array}\right)\right\} .
\end{aligned}
$$

Šios lygybès pirmasis narys lygus nuliui, nes vektoriaus, kurio reikšmès yra pastovios, kovariacijų matrica lygi nuliui. Parametrų apytikrių reikšmių vektoriai $\boldsymbol{T}$ ir $\boldsymbol{H}_{u}$ išlyginimo procedūrose išlieka pastovūs, t. y. const. Taigi antrojo lygybès (10) nario kovariacijų matrica yra lygi 


$$
\boldsymbol{K}\left\{\left(\begin{array}{c}
-A^{T} P \\
-C^{T} P \\
A_{r}
\end{array}\right) B\right\}=\left(\begin{array}{c}
-A^{T} P \\
-C^{T} P \\
A_{r}
\end{array}\right) K_{B}\left(-P A|-P C| A_{r}^{T}\right) .
$$

Kadangi $\boldsymbol{K}_{\boldsymbol{B}}=\boldsymbol{\sigma}_{0}^{2} \boldsymbol{P}^{-1}$, nes matavimų rezultatai yra nepriklausomi, tai lygybè (10), atsižvelgiant ị (11), užrašoma tokiu pavidalu:

$$
\begin{gathered}
\boldsymbol{K}_{\omega_{0}}=\sigma_{0}^{2}\left(\begin{array}{c}
A^{T} \\
C^{T} \\
-A_{r} P^{-1}
\end{array}\right)\left(P A|P C|-A_{r}^{T}\right)= \\
\sigma_{0}^{2}\left(\begin{array}{ccc}
A^{T} P A \mid & A^{T} P A \mid & -A^{T} A_{r}^{T} \\
C^{T} P A \mid & C^{T} P C & -C^{T} A_{r}^{T} \\
\hline-A_{r} A \mid & -A_{r} C \mid & A_{r} P^{-1} A_{r}^{T}
\end{array}\right)= \\
\sigma_{0}^{2}\left(\begin{array}{rr|r}
N_{11} & N_{12} \mid & -A^{T} A_{r}^{T} \\
N_{21} & N_{22} & -C^{T} A_{r}^{T} \\
-A_{r} A \mid & -A_{r} C & A_{r} P^{-1} A_{r}^{T}
\end{array}\right),
\end{gathered}
$$

čia $\sigma_{0}$ - matavimo rezultato, kurio svoris lygus vienetui, standartinis nuokrypis.

Taikydami (8) formulę, parametru pataisų vektoriu $\tau_{0}=\left(\tau^{T} \delta^{T} k^{T}\right)^{T} \quad$ galutiniu pavidalu nustatome iš (7) formulès.

Taikant papildomų parametrų pataisas $\delta$ ir sąlygines lygtis sumažěja pagrindinių parametrų $\tau$ tikslumas, nes tam tikra dalis matavimu procese gautos informacijos yra panaudojama papildomiems parametrams nustatyti. Aišku, dèl to nukenčia pagrindiniu parametru tikslumas. Tačiau taikant šias papildomas procedūras galima atlikti detalesnę geodezinių tinklų, šiuo atveju - aukščiu tinklų, analizę.

Pateiksime kovariaciju matricu pokyčiu rezultatus atvejais, kai netaikomi ir taikomi papildomi parametrai.

Iš lygčiu sistemų (4) arba (5) matyti, kad pagrindinių parametrų taškų aukščių pataisų vektoriaus $\tau$ kovariacijų matrica $\boldsymbol{K}_{\tau}$, kai netaikomi papildomi parametrai $\delta$ ir sąlyginès lygtys, yra šios išraiškos:

$$
\boldsymbol{K}_{\tau}=\sigma_{0}^{2} \boldsymbol{N}_{11}^{-1} .
$$

Vektoriaus $\tau$ kovariaciju matrica $\boldsymbol{K}_{\tau}^{\prime}$, taikant tik papildomus parametrus $\delta$ be salyginių lygčių, yra lygi

$$
\boldsymbol{K}_{\tau}^{\prime}=\boldsymbol{\sigma}_{0}^{2}\left(\boldsymbol{N}_{11}^{-1}+\boldsymbol{F} \boldsymbol{H}^{-1} \boldsymbol{F}^{\boldsymbol{T}}\right),
$$

čia $F=N_{11}^{-1} N_{12}, H=N_{22}-N_{21} N_{11}^{-1} N_{12}=N_{22.1}$.

Taigi iš formulių (13) ir (14) matyti, kad taikant papildomus parametrus $\delta$ pagrindiniu parametrų $\tau$ dispersijos padidèja dydžiu

$$
\Delta \boldsymbol{K}_{\tau, i i}^{\prime}=\sigma_{0}^{2}\left(\boldsymbol{F H}{ }^{-1} \boldsymbol{F}^{T}\right)_{i i}
$$

Nors taikant papildomus parametrus sumažèja nustatomu pagrindinių parametrų tikslumas, tačiau tokia procedūra padeda išsamiau atlikti geodezinių tinklų analizę, vertinti galimų klaidų šaltinius.

\section{Išvados}

1. Vertikaliujuc tinklų išlyginimo procedūrose taikant papildomus parametrus ir sąlygines lygtis yra galimybe analizuoti matavimu sistemingassias klaidas. Tokiai analizei atlikti panaudojama tam tikra dalis matavimu informacijos, todèl dèl šios operacijos sumažeja pagrindinių parametrų tikslumas.

2. Straipsnyje pateikiamos kovariaciju matricu išraiškos, pagal kurias galima îvertinti pagrindinių bei papildomu parametrų tikslumo rodiklių pokyčius, kai vertikalusis tinklas išlygintas taikant papildomus parametrus ir sallygines lygtis.

\section{Literatūra}

1. MORITZ, H. Geodetic Reference System 1980. Bulletin Geodesique, the Geodesists Handbook. International Union of Geodesy and Geophysics, 1988, p. 348-358.

2. KOCH, K. R. Einführung in die Bayes-Statistik. SpringerVerlag, Berlin Heidelberg, 2000. 225 S.

3. ЯКОВЛЕВ, Н. В. Высшая геодезия. Москва: Недра, 1989. $446 \mathrm{c}$.

4. ADAM, J.; AUGATH, F.; BROUWER, A. A. Status and Development of the European Height Systems. LAG Symposia, 2000, Vol 121, Geodesy Begon. Springer: Berlin Heidelberg, p. 55-60.

5. PETROŠKEVIČIUS, P. Sunkio anomalijų ir pagreičio redukavimas. Geodesy and Cartography (Geodezija ir kartografija), 2000, Vol XXVI, No 4, p. 167-170 (in Lithuanian).

6. SKEIVALAS, J. Treatment of correlated geodetic measurements (Koreliuotų geodezinių matavimų rezultatų matematinis apdorojimas). Vilnius: Technika, 1995. 272 p. (in Lithuanian).

Jonas SKEIVALAS. Prof, Doctor Habil. Vilnius Gediminas Technical University. Dept of Geodesy and Cadastre, Sauletekio al. 11, LT-10223 Vilnius, Lithuania. $\mathrm{Ph}+37052744$ 703, Fax +370 52744 705,

e-mail: jonas.skeivalas@ap.vgtu.lt.

Author of two monographs and more than 130 scientific papers. Participated in many intern conferences and research visits to the Finish Geodetic Institute.

Research interests: processing of measurements with respect to tolerances, adjustment of geodetic networks. 